\title{
Integrating Qualitative and Quantitative Methods in Participatory Modeling to Elicit Behavioral Drivers in Environmental Dilemmas: the Case of Air Pollution in Talca, Chile
}

\author{
Franziska Meinherz $\mathbb{D}^{1} \cdot$ Nuno Videira $\mathbb{D}^{2}$ \\ Received: 1 March 2017 / Accepted: 26 March 2018 \\ (c) Springer Science+Business Media, LLC, part of Springer Nature 2018
}

\begin{abstract}
The aim of this paper is to contribute to the exploration of environmental modeling methods based on the elicitation of stakeholders' mental models. This aim is motivated by the necessity to understand the dilemmas and behavioral rationales of individuals for supporting the management of environmental problems. The methodology developed for this paper integrates qualitative and quantitative methods by deploying focus groups for the elicitation of the behavioral rationales of the target population, and grounded theory to code the information gained in the focus groups and to guide the development of a dynamic simulation model. The approach is applied to a case of urban air pollution caused by residential heating with wood in central Chile. The results show how the households' behavior interrelates with the governmental management strategies and provide valuable and novel insights into potential challenges to the implementation of policies to manage the local air pollution problem. The experience further shows that the developed participatory modeling approach allows to overcome some of the issues currently encountered in the elicitation of individuals' behavioral rationales and in the quantification of qualitative information.
\end{abstract}

Keywords Behavioral drivers $\cdot$ Qualitative research methods $\cdot$ Participatory modeling $\cdot$ System dynamics modeling $\cdot$ Urban air pollution $\cdot$ Talca, Chile

\section{Introduction}

Socioenvironmental systems are driven by the interdependencies between the interests of the actors within it (Martínez-Alier and Muradian 2015; Vidal-Legaz et al. 2013; Paavola and Adger 2005; Crance and Draper 1996;

Electronic supplementary material The online version of this article (https://doi.org/10.1007/s00267-018-1034-5) contains supplementary material, which is available to authorized users.

Franziska Meinherz

franziska.meinherz@epfl.ch

1 HERUS, Laboratory for Human-Environment Relations in Urban Systems, Institut d'ingénierie de l'environnement IIE, Faculté de l'environnement naturel, architectural et construit ENAC, Ecole Polytechnique Fédérale de Lausanne, Lausanne, Switzerland

2 CENSE, Center for Environmental and Sustainability Research, Departamento de Ciências e Engenharia do Ambiente, Faculdade de Ciências e Tecnologia, Universidade NOVA de Lisboa, 2829516 Caparica, Portugal
Lemons 1989), and by the aggregated outcomes of the decisions of the individual actors. Such decisions take place in a context of high complexity, characterized by a multitude of individual motivations and needs, which an individual prioritizes situationally (Elsawah et al. 2015; Stave 2010; Renn and Schweizer 2009). Consequently, specific motivations or attitudes might fail to result in corresponding actions depending on situational factors, such as a perceived or real incapacity to act, a misperception of the situation or the available action strategies, or the lack of a feeling of personal responsibility (Popa 2015; Kollmuss and Agyeman 2002; Ringrose et al. 1996). Environmental problems can thus be understood as the consequence both of conflicting interests or values between individuals, as well as the dilemmas present in the decision-making of one person. Indeed, it has been noted that environmental problems can be the consequence of the dilemmas that a person faces when trying to balance her different values and motivations, as well as due to the ambiguity that can exist regarding the origins, state, and possible solutions to the problem (Popa 2015; Paavola and Adger 2005; Crance and Draper 1996; 
Ajzen 1991; Max-Neef 1991; Lemons 1989, Giordano et al. 2017)

The focus of this paper is on the different rationales that play into the decision-making of one person, and on how the interaction between these decision-making rationales with the wider decision-making context-aggregated societal behavior and governmental policies-can result in dilemmas that lead to environmental problems. Environmental policies are part of the context in which individuals weigh their different decision arguments and decide on a specific course of action. To disregard the complexity of the motivations that drive individuals' behavior might result in environmental management strategies that crowd out proactive motivations. It is, therefore, important to understand the underlying motivations and needs shaping individuals' decision-making domain (Elsawah et al. 2015; Popa 2015; Reed et al. 2009; Cárdenas et al. 2000, Giordano et al. 2017).

Urban air pollution caused by transportation or household practices is an illustrative problem exemplifying such environmental problems. Particulate matter pollution is often caused by a large number of relatively small emission sources (nonpoint emission sources; Chávez et al. 2011; Shortle and Horan 2001) and has proven to be a complex problem, in which the emitters are at the same time the victims of the pollution, which complicates policy interventions (Chávez et al. 2011; Santos et al. 2006). This points to people facing contradictory behavioral driversthey indeed put their own health at risk with their behavior. This points to the complexity of the underlying individual decision-making dilemmas that people face in the context of such an environmental problem. The complexity of urban air pollution inspired many researchers to analyze the problem from a systemic perspective or by focusing on the individual behavior. However, the studies that took a systemic approach and looked at the dynamics of different subsystems mostly failed to take into account the drivers of the individual behavior and how these depend on these systemic dynamics (e.g., Sanhueza et al. 2015; Armah et al. 2010; Stave 2010; Shahgholian and Hajihosseini 2009; Chen et al. 2006). Consequently, they did not account for the dilemmas that a person faces when trying to reconcile her conflicting values and interests. On the other hand, studies that analyzed the problem from a perspective focusing on the individual behavior mostly disregarded systemic inter-relations and additionally assumed a behavioral ideal-type close to the homo economicus, thus neglecting the complexity inherent to human behavior (e.g., Gómez et al. 2013; Chávez et al. 2011; Chávez et al. 2009).

The complex inter-relations between the socioenvironmental context, a person's decision-making dilemmas, and environmental policies are characterized by feedbacks and important nonlinearities, making them hard to capture with linear or static models. Dynamic simulation models are thus an invaluable tool for environmental policy design, since such models show how the complex interrelations of the different system elements may lead to unexpected medium and short-term effects and can help to anticipate possible rebound effects or policy resistance (Dupont et al. 2016; Elsawah et al. 2015; Xu et al. 2015; Stave 2010; Leal Neto et al. 2006; Costanza and Ruth 1998). To adequately represent these feedbacks, it is essential that the models capture the world as it is seen by the actors, in order to grasp how their subjective reality evolves with the context. It is thus essential to include the actors in the process (Elsawah et al. 2015; Stringer et al. 2014; Videira et al. 2010; Jones et al. 2009; Renn and Schweizer 2009; Sterman 2000; Lemons 1989). This also ensures that the problem is framed in terms that are of relevance to the actors and that the solution domain takes into account their different interests and priorities (Santos et al. 2006; Videira et al. 2006; Stern and Fineberg 1996).

There is thus a need for approaches that allow to elicit qualitative information on people's interests and motivations, and to use this information for the development of quantitative dynamic simulation models. Voinov and Bousquet (2010) reviewed several types of stakeholderbased modeling approaches, including group model building and companion modeling, which are underpinned by different simulation modeling languages. Companion modeling (Becu et al. 2005; Bousquet et al. 1999; Le Page et al. 2014) uses agent-based models and role-playing games to build shared stakeholder representations of complex systems. It focuses on simulating the interactions between multiple autonomous agents using a rule-based approach (Kelly Letcher et al. 2013). On the other hand, group model building uses System Dynamics methods and tools to formalize stakeholders' mental models into dynamic simulations (Chen et al. 2014; Andersen and Richardson 1997; Vennix 1996). The focus of this modeling perspective is placed on identifying the feedback structures and cause-effect relationships governing systems' dynamic behavior at an aggregated level.

Group model building is one application of system dynamics modeling and has been mostly used as a tool for creating a consensual understanding of a problem situation between different stakeholders and for increasing the stakeholders' commitment to a decision (Chen et al. 2014; Carmona et al. 2013; Jones et al. 2009; Rouwette et al. 2002; Coyle 2000; Vennix 1990). In group model building, the group consensus on a problem definition and model feedback structure constitutes a form of validation, thus overcoming some of the problems that have been put forward to discourage the development of quantitative models based on purely qualitative information (Luna-Reyes and Andersen 2003; Coyle 2000). 
This paper aims to complement these existing approaches that focus on environmental problems characterized by interpersonal decision-making dilemmas with one that focuses on environmental problems mainly driven by intra-personal decision-making dilemmas, that result from the interaction between a person's decision-making rationales with her wider decision-making context, and notably with the environmental policies that shape this context. The approach that we propose integrates qualitative and quantitative methods for eliciting individuals' rationales and translating them into a System Dynamics model, which highlights a person's potentially conflicting rationales and provides support for environmental policy decisions. The proposed approach uses focus groups to collect qualitative information on the complexity and dilemmas inherent to individuals' mental models, as well as grounded theory to code this information and to translate it into hypotheses based on which a quantitative simulation model can be developed. It concludes by testing the model's hypotheses and their implications in interviews with some of the original focus group participants. The approach was applied in a case study related to the management of urban air pollution caused by residential heating with wood in central Chile.

The paper is structured as follows. In the next section, we present the different methodological tools that we drew on to develop our approach, and explain how we integrated these methods in our approach. We continue by providing background information on the case to which we applied our approach. The results of applying the approach to the case study are then presented, followed by a discussion of the implications of these results, namely with regard to the appropriateness of the proposed approach and its application to the management of environmental problems driven mainly by the decision-making dilemmas that people face in their daily lives.

\section{Applied Methods and their Integration in the Research Approach}

In this section, we first briefly present the different methodological tools that we drew upon in the development of the proposed approach, and explain why we considered them adequate for the stated purpose. We then illustrate how these different methodological tools were integrated in a participatory process that constitutes the core of the approach.

\section{Overview of Research Methods}

\section{Focus groups}

In focus groups, the discussion is driven by the group, and not by the researcher, which allows participants to set their priorities and establish their framework of analysis as the norm (Romm 2015; Kitzinger 1994). Having participants interacting among equals fosters the feeling of a shared struggle and facilitates the discussion of sensitive issues, thus making it likely that discrepancies between expressed behavior and actual behavior are unearthed. This is also the reason why for the composition of a focus group, relatively homogenous participants, whose lived experiences can expected to be similar, should be chosen (Farnsworth and Boon 2010; Kitzinger 1994, Kind 2004). In that way, focus groups can thus produce insights that are likely to remain hidden in individual interviews (Kind 2004; Vennix 1996). Furthermore, focus groups do not aim at consensus or closure, but rather at conserving the diversity of people's perspectives and the co-existence of different perceptions (Romm 2015; Kind 2004). Hence, focus groups are often used when data are needed on how people think about something and why they think about it in that way (Kitzinger 1994), when people's motivations and lifestyles need to be explored (Kind 2004), and when information on their behavioral rationales is needed (Romm 2015). These methodological advantages of focus groups were the reason why the method was chosen to elicit data on people's decision-making strategies in the face of an environmental dilemma, and the values, constraints, and considerations that they draw upon and face in this context.

\section{Grounded theory}

Several lexical analyses and knowledge engineering methods have been used to identify and formalize the knowledge of stakeholders in participatory modeling approaches. In companion modeling, for instance, processing knowledge elicited from stakeholder interviews has been based on associative networks and coding procedures leading to a conceptual model, or class diagram, that serves as the basis for building the computer-assisted role-playing game (Becu et al. 2005; Dray et al. 2006; Le Page et al. 2014). Since the aim here was to first translate elicited knowledge into a causal loop diagram, the grounded theory procedure that was selected followed the technique proposed by Kim and Anderson (2012). The Grounded theory aims at identifying themes in text data (Luna-Reyes and Andersen 2003). First, text segments are labeled to find angles pointing toward an analytical framework. Second, this emerging framework is used to organize and summarize the data. This procedure ensures that the analytical framework represents the perspective of the interview partners or focus group participants (Charmaz 2006). The goal is thus to induce theories from observation. This means that the theories are likely to be context-specific. Grounded theory has found to be an apt tool to translate interview transcripts into causal diagrams, because its rigorous method allows to overcome issues such 
as the need to homogenize different terms referring to the same concept and to introduce structure mentioned only implicitly in the text (Kim and Anderson 2012). Nonetheless, attention has to be paid on how to maintain the linkages between the qualitative data and the causal diagram or map (Luna-Reyes and Andersen 2003). Inspired by these positive precedents of applying grounded theory to translate qualitative text data into causal loop diagrams, we decided to follow suit, and to use this method in our approach, by using it to code the focus group transcripts.

\section{System dynamics modeling}

System dynamics modeling is a problem-based approach that assumes that problems originate from the system's underlying structure, meaning the environmental constraints, social norms, and pressures that shape people's behavior (Meadows 1976). The method allows capturing the dynamics resulting from the inter-relations between the different system elements (Videira et al. 2010; Leal Neto et al. 2006; Costanza and Ruth 1998). Decisions are explicitly modeled and are generally based on three elements - the desired state of the system, the observed state of the system, and the control of an action-which in turn affects the state of the system (Forrester 1992). System dynamics models aim at representing the system such as it is perceived by the actors. To ensure this, the actors should be involved in the modelbuilding process (Sterman 2000; Forrester 1992; Meadows 1976). For our purpose, we decided to use system dynamics modeling because it allows to explicitly model the different rationales that a person considers in her decision-making process, and highlights the contradictions inherent to them.

\section{Combining Methods in a Participatory Process}

Figure 1 outlines the proposed participatory process developed for eliciting individuals' behavioral drivers in the context of an environmental dilemma, and for incorporating them in a dynamic simulation model. The stages outlined on the left correspond to the steps of a typical system dynamics modeling process (e.g., Mostashari and Sussman 2005; Sterman 2000), while the items on the right highlight the key innovative tasks associated with each step that have been integrated in the present research. As can be seen in Fig. 1, the process is cyclical, with the model structure being revisited in follow-up interviews with some of the original focus group participants. The proposed novel tasks in each step of the modeling process are outlined below in more detail.

\section{Data collection}

The aim of this step is to elicit information on individual's motivations, behavioral drivers, and their actual behavior in

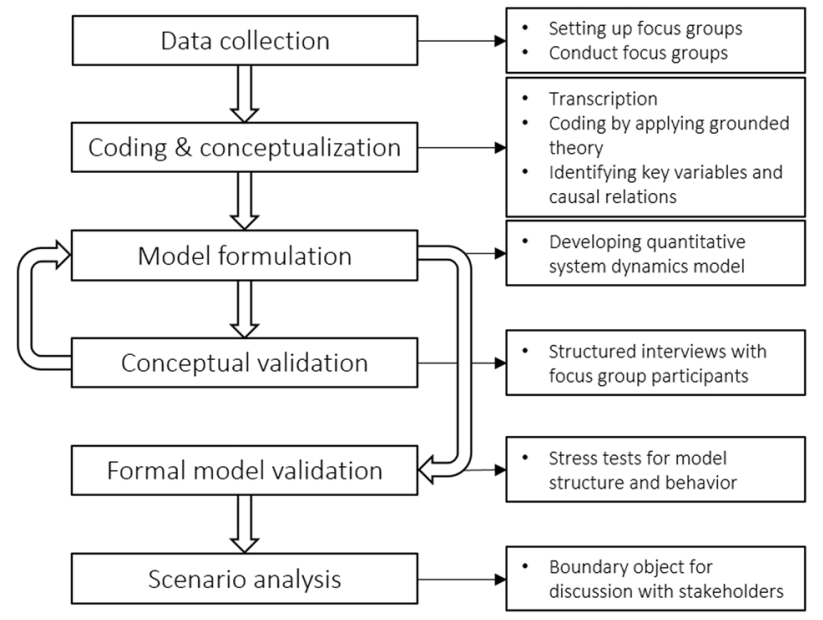

Fig. 1 The proposed participatory modeling process

specific situations. Focus groups were selected as a method to this purpose. During the focus groups, a script is used that contains the key points to be raised during the discussion, as well as the desired knowledge outcome for each point, and which can be found in appendix A. In order to facilitate the use of the focus group data for the development of a quantitative simulation model, the focus group script contains strategies inspired by group model-building techniques, which are also outlined in appendix A. The focus group participants are selected with the help from representatives of the local communities. Attention is paid to having low intragroup variability between the participants, while having focus groups from different socioeconomic categories. With this, we hope to capture different realities that exist in the case study, while defining groups in which people truly discuss among equals-which should foster the emergence of unanticipated information on their decision-making dilemmas.

\section{Coding and conceptualization}

The aim of this step is to code the data from the focus groups to prepare it for the development of a simulation model. The focus group recordings are transcribed. Themes are identified using the grounded theory, and the data are organized accordingly. In a second step, the data are coded afresh, by identifying variables and causal relationships in text fragments (c.f. Kim and Anderson 2012), resulting in the development of causal loop diagrams. On the basis of the identified themes, variables, and their causal relations, hypotheses are formulated based on which a dynamic simulation model is developed.

\section{Model formulation}

The aim of this step is to develop a dynamic simulation model that can be used to better understand the drivers of 


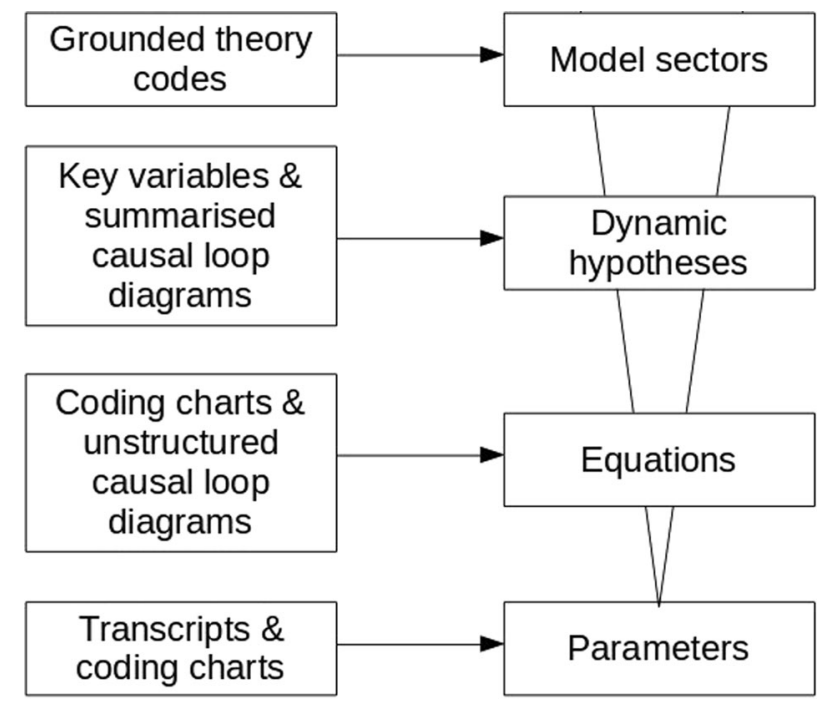

Fig. 2 Main elements of the model development process departing from coded focus groups data

individuals' rationales and their behavior in the context of an environmental dilemma. Figure 2 illustrates how the results from the qualitative coding exercise are used for the development of the model.

\section{Conceptual validation}

Policies can only be tested if the model output results from a structure that corresponds to the system's properties. A structural validation is thus essential (Barlas 1996). Validation interviews are conducted with participants from the original focus groups, to evaluate whether the model structure and behavior are consistent with their perceptions. The interviews are structured in a way that fosters participants' critical evaluation of the model (c.f. Andersen et al. 2012), as outlined in the script presented in appendix A. The model is consequently adjusted to incorporate participants' comments. The interviews are further used to identify the key areas of uncertainty in the model, which are incorporated in the scenario analyses.

\section{Formal model testing}

The model is evaluated on the one hand concerning its suitability to the purpose - to inform the design and implementation of an environmental policy-the integrity of the modeling process, and its sensitivity to uncertainty in assumptions (Sterman 2000), as well as regarding the stability of its structure, the formulation of the equations, and the behavior under extreme conditions (Sterman 2000; Barlas 1996).

\section{Scenario analysis}

The aim of this step is to culminate the modeling process by producing tangible insights on how individuals' behavioral drivers affect the management of the environmental problem. Two categories of scenarios are proposed: (1) scenarios to evaluate the impact of model uncertainty on the model output and (2) scenarios to evaluate the impact of different management options.

\section{The Case: Urban Air Pollution in Talca, Chile}

Talca is a medium-sized city located in the Maule province in central Chile, in a closed basin formed by the Andes mountains and the coastal mountain range, as is indicated in Fig. 3. This means that most winds pass over the city; a fact that facilitates the accumulation of air pollutants. The Maule province has a Mediterranean climate with hot and dry summers and cold and rainy winters (Ministerio del Medio Ambiente 2015).

Roughly half the households use wood for heating, and the resulting particulate matter emissions are the major cause of air pollution in Talca, with residential heating with wood accounting for $46.7 \%$ of the total $\mathrm{PM}_{10}$ and $75.6 \%$ of the total $\mathrm{PM}_{2.5}$ emissions (Universidad de Concepción 2014). Many of the stoves used for heating have very poor emission standards, and many households use wood, which is still humid and thus emits relatively more particulates upon combustion. In addition, much of Talca's population lives in individual houses with very poor insulation standards, resulting in a high demand for heating energy (Universidad de Concepción 2014). Consequently, the daily and yearly particulate matter concentration repeatedly violate the daily and yearly norms for $\mathrm{PM}_{10}$ concentration, which are established at 150 and $50 \mu \mathrm{g} / \mathrm{m}^{3}$, respectively, as indicated in Figs. 4 and 5 (Ministerio del Medio Ambiente 2015).

For this study, the following three neighborhoods indicated in Fig. 3 were considered: Lircay, La Florida, and San Miguel del Piduco. Most of Talca's middle class lives in La Florida, which is also the area with the highest levels of air pollution (c.f. Figures 4 and 5). San Miguel del Piduco and Lircay are relatively poor neighborhoods. San Miguel del Piduco faces levels of air pollution close to $\mathrm{La}$ Florida, while Lircay is a bit less exposed to it (c.f. Figs. 4 and 5). The center of Talca was destroyed in an earthquake in 2010 and now hosts only commercial buildings and no residents.

Because of the high levels of air pollution measured in Talca, the Ministry of the Environment commissioned a "Plan for Clean Air" (Plan de descontaminación atmosférica) for the city. This plan comprises different management policies (Ministerio del Medio Ambiente 2014), including:

Air-quality alarms-When the level approaches the daily norm or are beyond it, the city declares a local prohibition to 


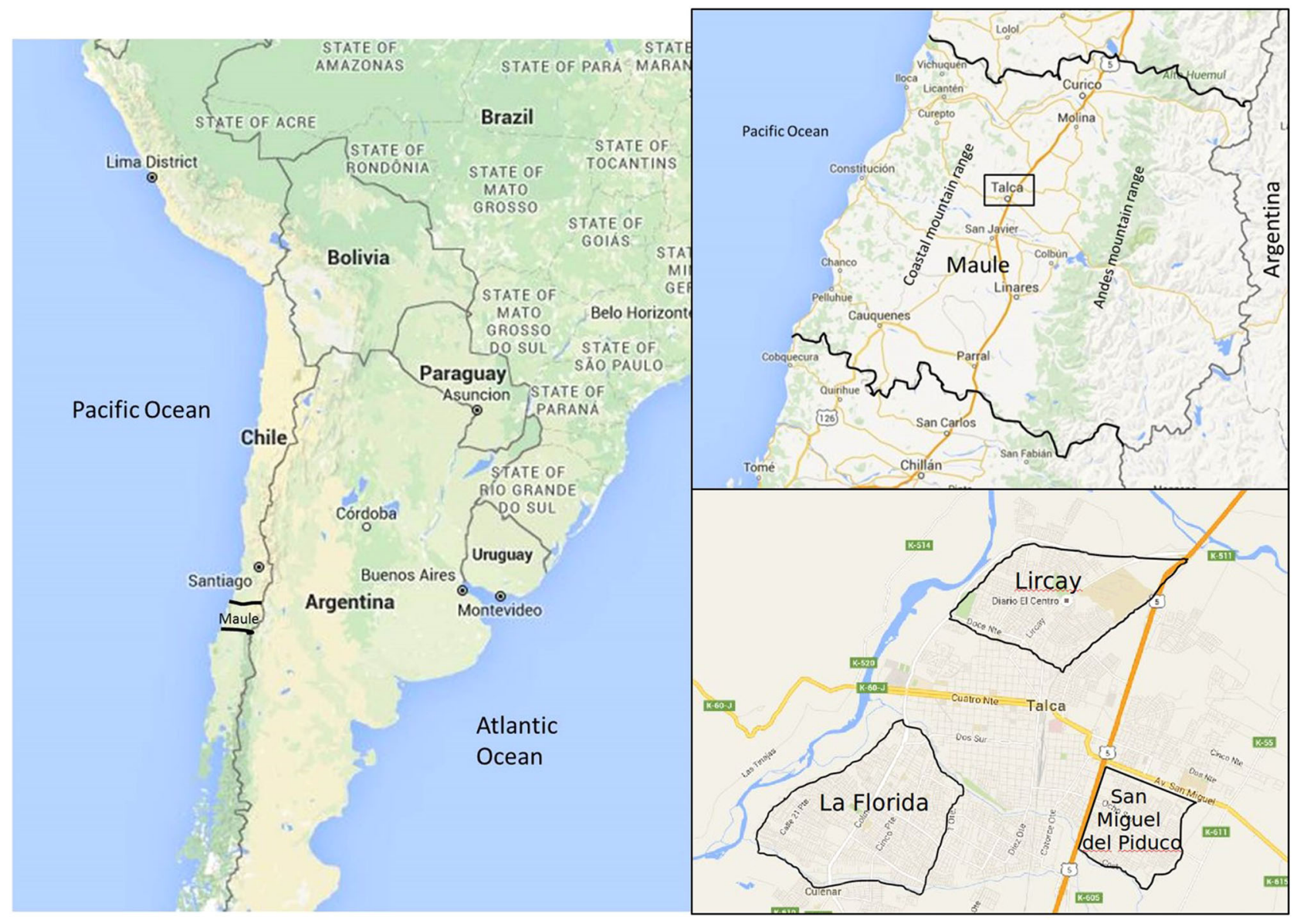

Fig. 3 Maps of Chile, Maule, and Talca. Figure conceived by the authors based on adjusted map material from Google Maps

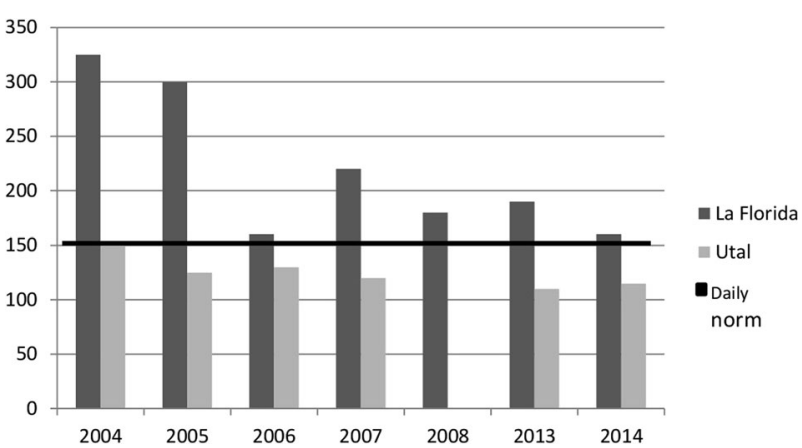

Fig. 4 Daily concentration of $\mathrm{PM}_{10}$ in Talca (in $\mu \mathrm{g} / \mathrm{m}^{3}$ ). Figure conceived by the authors based on data from Ministerio del Medio Ambiente (2015). Note that Utal is located in Lircay (c.f. Figure 3)

burn wood. To enforce the alarms, the police patrols the street and monitors the chimneys. Violations are punished by fines (Ministerio del Medio Ambiente 2014);

Replacement of wood stoves with pellet stoves-To achieve a switch to a less contaminating heating technique, 13,000 subsidies on pellet stoves were granted by the Ministry of the Environment, with the aim to substitute a significant amount of wood stoves with pellet stoves by

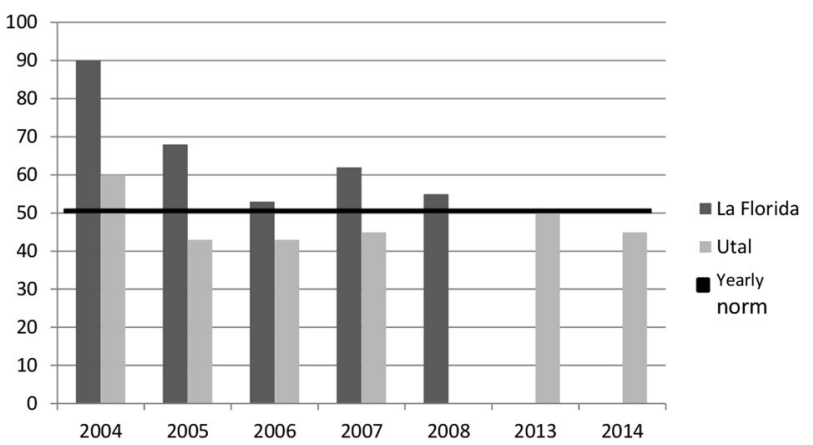

Fig. 5 Yearly concentration of $\mathrm{PM}_{10}$ in Talca (in $\mu \mathrm{g} / \mathrm{m}^{3}$ ). Figure conceived by the authors based on data from Ministerio del Medio Ambiente (2015). Note that Utal is located in Lircay (c.f. Figure 3)

2020. Upon obtaining the subsidy, a household has to hand in its wood stove, which will be destroyed by the government (Ministerio del Medio Ambiente 2015).

Insulation of the houses-To improve the energy standard of the houses, 30,000 subsidies were granted by the Ministry for Housing and Urbanization. This corresponds to a prolongation of an already existing policy, which also granted subsidies on insulation. The subsidy funds the 
improvement of the insulation of existing houses (Ministerio del Medio Ambiente 2015).

For this case study, it was analyzed how individuals' behavioral drivers regarding heating interact with the different policy measures included in the plan.

\section{Results}

\section{Insights From the Focus Groups}

\section{The set-up of the focus groups}

Five focus groups were organized, with people from two different socioeconomic categories (middle-class households and economically vulnerable households). The focus groups with people from economically vulnerable households took place in Lircay and San Miguel del Piduco, whereas the focus groups with participants from middle-class households were held in La Florida, where almost all of Talca's middle class lives. To recruit the focus group participants, local neighborhood association representatives were contacted and instructed on the sampling criteria for the focus group participants. In this process, their experience with the context of the case study was considered in that the sampling criteria were partly adjusted to their feedback. We asked the neighborhood association representatives to recruit 8-12 participants per focus group, with the participants of each focus group being socioeconomically relatively homogenous, and living in houses of similar sizes. For Lircay and San Miguel del Piduco, we looked at household living in single-storey one-family detached houses, which is the dominant house type in these neighborhoods. For La Florida, we looked at two-storey one-family detached houses, which is the dominant house type in this neighborhood. The neighborhood association representatives further suggested to mainly invite women, since decisions regarding heating fall into their responsibility. At the beginning of each focus group, informed consent was obtained from the participants to be recorded and for the recordings to be used in the context of this research. Table 1 gives an overview of the composition of each focus group.

\section{Results from the focus groups}

In the following, the key insights from the focus groups are presented. A table with a synthesis of the focus group data is provided in appendix $\mathrm{B}$. The axes along which the table in appendix B and the following summary are organized were identified by applying the grounded theory to identify themes in the focus group transcripts.

The past: The origin of the problem While heating with wood has often been portrayed as a regional tradition (e.g., Chávez et al. 2009; Chávez et al. 2011; Gómez et al. 2013; Universidad de Concepción 2014), the focus group results showed that particularly the middle-class households still remember when they started heating with wood roughly 20 years ago. Before, households used paraffin stoves or coal grills for heating. The main reasons for switching to wood stoves were the arrival on the market of affordable wood stoves of decent quality, and the relative cheapness of wood compared to paraffin, of which the price increased significantly at that time. This thus led to a replacement of the then existing stock of stoves with wood stoves. The amount of wood stoves further increased substantially because also the population of Talca increased by more than $30 \%$.

Both participants from the middle class and from the lower class also stated that the air pollution problem was mainly a middle-class problem, since the lower class did not have enough income to buy enough wood to cause an air pollution problem. This is consistent with the air pollution data collected by the two monitoring stations in the city (c.f. Figs. 4 and 5). The middle-class households further complained that the subsidies on pellet stoves and insulation were primarily given to low-income households, even though they were not actually the ones causing the problem.

The status quo: why people keep polluting themselves In all focus groups, people were concerned about the air pollution problem, and in four out of the five groups, the participants claimed to suffer a lot from it, and associated it with respiratory problems such as asthma, eye irritations, and a bad odor sticking to walls, clothes, and furniture. Participants also identified their own behavior as the key problem cause. Only in Lircay did the participants blame the industry and bakeries for the pollution. In the

Table 1 Characteristics of the focus groups

\begin{tabular}{|c|c|c|c|c|c|}
\hline & Lircay & S. M. del Piduco & La Florida (1) & La Florida (2) & La Florida (3) \\
\hline Group size & 10 & 11 & 12 & 9 & 8 \\
\hline Gender (f/m) & $6 / 4$ & $11 / 0$ & $11 / 1$ & $8 / 1$ & $8 / 0$ \\
\hline Approximate age range & $20-80$ & $30-80$ & $40-80$ & $50-60$ & $40-70$ \\
\hline Socioeconomics & Poor & Poor & Middle class & Middle class & Middle class \\
\hline
\end{tabular}


middle-class groups, participants repeatedly asked for a radical change and the abolition of wood, because they no longer wanted to be exposed to such high levels of air pollution. Nonetheless, participants were very reluctant to initiate such a change themselves, and the reasons they mentioned for this were the high cost of the alternatives (e.g., gas, electrical, or paraffin stoves), and the advantages of wood (e.g., dries the house, allows to dry laundry, nice atmosphere in the room, large heat radius, and can be used for cooking tea).

While the middle-class participants were convinced of the necessity of air-quality alarms, they also complained that because of the frequent air-quality alarms, they were not able to heat with wood much anymore, and also had to use an electrical, gas, or paraffin stove to heat their homes. The households from the low-income neighborhoods explained that in their neighborhoods, air-quality alarms were either not declared or not enforced, and that since many of them were cooking with wood in winter, they would not be able to respect them anyways. They mainly liked wood stoves because they take every kind of combustible, be it wood, coal, or trash, and therefore allow them to minimize their heating expenditures.

The future: how the households would solve the problem As most participants recognized their own behavior as the key problem cause, they wanted governmental assistance in a behavioral change, but were critical of the program to change wood for pellet stoves. They criticized the high cost of pellets and quite some participants were unsure whether the pellet, which is a wood derivative, would solve the air pollution problem. The low-income households also criticized that the pellet was only available in a supermarket in the south of the city, which they could not reach due to the lack of a car. Many participants were also reluctant to give up their wood stoves, which were still functional and in which they had invested money.

Overall, the participants liked the idea of receiving a subsidy, but wanted the subsidy to be for gas or electricity, so that they could switch to these alternatives, in which they had faith, but which they perceived as very expensive. Some middle-class participants mentioned that they would be willing to give the pellet stove a try despite their doubts, but that since the subsidies were primarily given to lowincome households, they could not afford the switch.

All participants were very much in favor of the subsidy on insulation, and were very keen on obtaining it. Yet again, the middle-class households complained that since priority was given to low-income households, they were not actually able to procure it. It is worth noting that in almost all focus groups, there was at least one participant who had already received the insulation subsidy, and who was very happy with it.

\section{Translating the Focus Group Data Into Model Structure}

To translate the focus group data into model structure, the first step was to identify variables and their causal relationships. After having identified themes in the focus group data by using grounded theory, the transcripts were broken down into causal arguments. Variables were identified in text fragments and classified as either descriptive, cause, or effect variables. In charts, the variables were recorded as the original text fragments, and it was indicated whether the cause and effect variables were positively or negatively related. The causal relations thus identified were mapped into preliminary and unstructured word-and-arrow diagrams (also called causal loop diagrams or CLDs) by using the software Vensim from Ventana Systems. In this preliminary version of the CLDs, all identified arguments were preserved. Our strategy to recruit focus group with low intragroup variability paid off, in that there were hardly any contradictions in the arguments. A major challenge in consolidating the CLDs consisted, however, of resolving ambiguities in the argumentations of the participants, which complicated the identification of clear polarities. One such instance was the same participants mentioning both that using dry wood leads to less air pollution, and that all combustion of wood-dry or not—causes air pollution. The first version of the statement-ceteris paribus, the combustion of dry wood leads to less air pollution-thus contradicts the second version-ceteris paribus, the combustion of any kind of wood leads to more air pollution. In a next step, the wording was homogenized across the participants of each focus group. This step resulted in five CLDs showing the insights from each focus group. The unstructured CLDs were again compared to the focus group transcripts to check for implicitly mentioned relationships, and were adjusted accordingly.

The 'causes tree' and 'uses tree' tools of Vensim were used to identify key variables (e.g., "use of wood", "heating expenditures"), by looking for those that played crucial roles in the system. On the basis of these key variables, and by using the 'loop' tool of Vensim, the main feedback structures of each CLD were mapped. Lastly, the key exogenous inputs to each of the identified key loops were identified by again looking at the unstructured diagrams. This resulted in simplified and summarized CLDs for each focus group, which contained the key information on the behavioral drivers of the participants. Figure 6 provides an example of such a diagram. Note that following the typical CLD notation (Sterman 2000), arrows with plus signs indicate positive causal relations between two variables, and arrows with minus signs negative causal relations.

The CLDs achieved at this stage constitute tentative dynamic hypotheses regarding the causal structure of the 


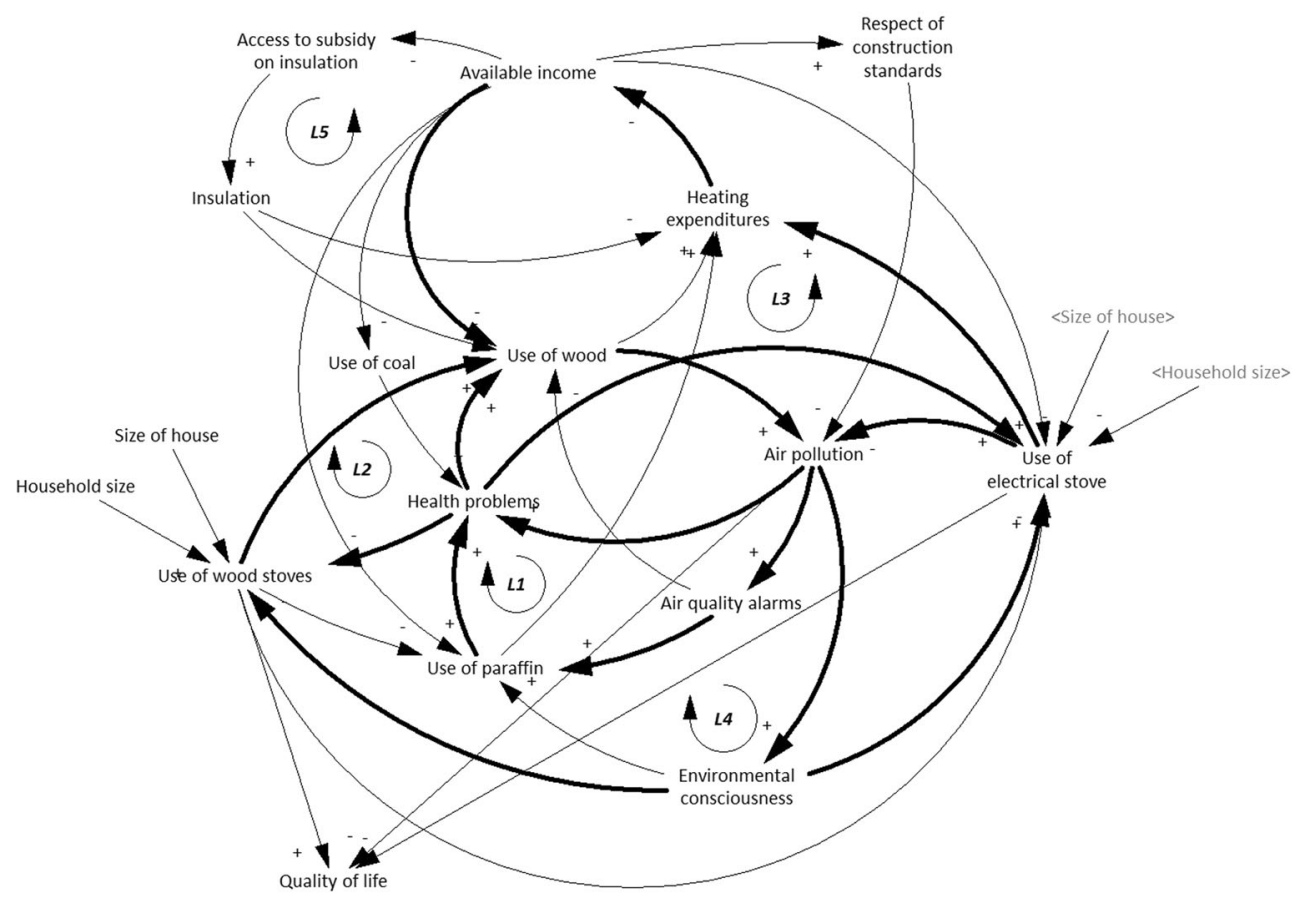

Fig. 6 Example of a simplified CLD obtained from the focus group data

problem, based on which a first simulation model could be developed. Parameter values were taken from the focus group transcripts and from official reports on the air pollution problem (c.f. Ministerio del Medio Ambiente 2014, 2015; Universidad de Concepción 2014). To evaluate whether the model hypotheses adequately represent the households' behavioral drivers, follow-up group interviews with the available members of the original focus groups were conducted. The interview script included results of preliminary model runs and an enumeration of the model hypotheses. The interviewees also weighted different decision arguments expressed in the model's equations and estimated parameter values for which information was missing. The model was then adjusted accordingly.

Lastly, the model structure was formally tested regarding the plausibility of its output, the consistency of its algorithms in extreme cases, and regarding its sensitivity to variations in the parameter values. Test runs showed that the model's output replicated the average energy consumption, the average inside temperature, and the average wood consumption identified in a report on residential heating in Talca (Universidad de Concepción 2014). The tests provided satisfactory results, and the insights from the sensitivity analyses were incorporated in the scenario analysis, to evaluate their implications.

In the following section, the simulation model is briefly explained, after which the results of the scenario analyses are discussed.

\section{Insights from Modeling and Simulation}

\section{The simulation model}

The model's purpose was to analyze which behavioral rationales interrelate in a household's decision-making process regarding heating, as well as their inter-relations with the different governmental management options for the air pollution problem. The focus groups showed that, while the priorities, rationales, and decision-making dilemmas of households of the middle-income and low-income class were relatively homogenous, respectively, they differed a lot between these two classes. Consequently, the decisionmaking mechanisms of the households from these two social classes were modeled separately. The model illustrates the decision-making process of a middle-income and low-income household, respectively, as well as its inherent dilemmas. Figure 7 presents a summary of the model. In its lower-hand right corner, the decision-making process of a middle-income household is illustrated, and in the lowerhand left corner the one of a low-income class. The model extrapolates the decision of an individual household to obtain the general trend in that social class, in order to get a measure of total air pollution, as well as of the amount of pellet stove users in the respective social class. The latter was an important element of decision-making, in so far as it had emerged during the focus groups that mouth-to-mouth propaganda was the way of communication that households most rely on to form opinions regarding specific 


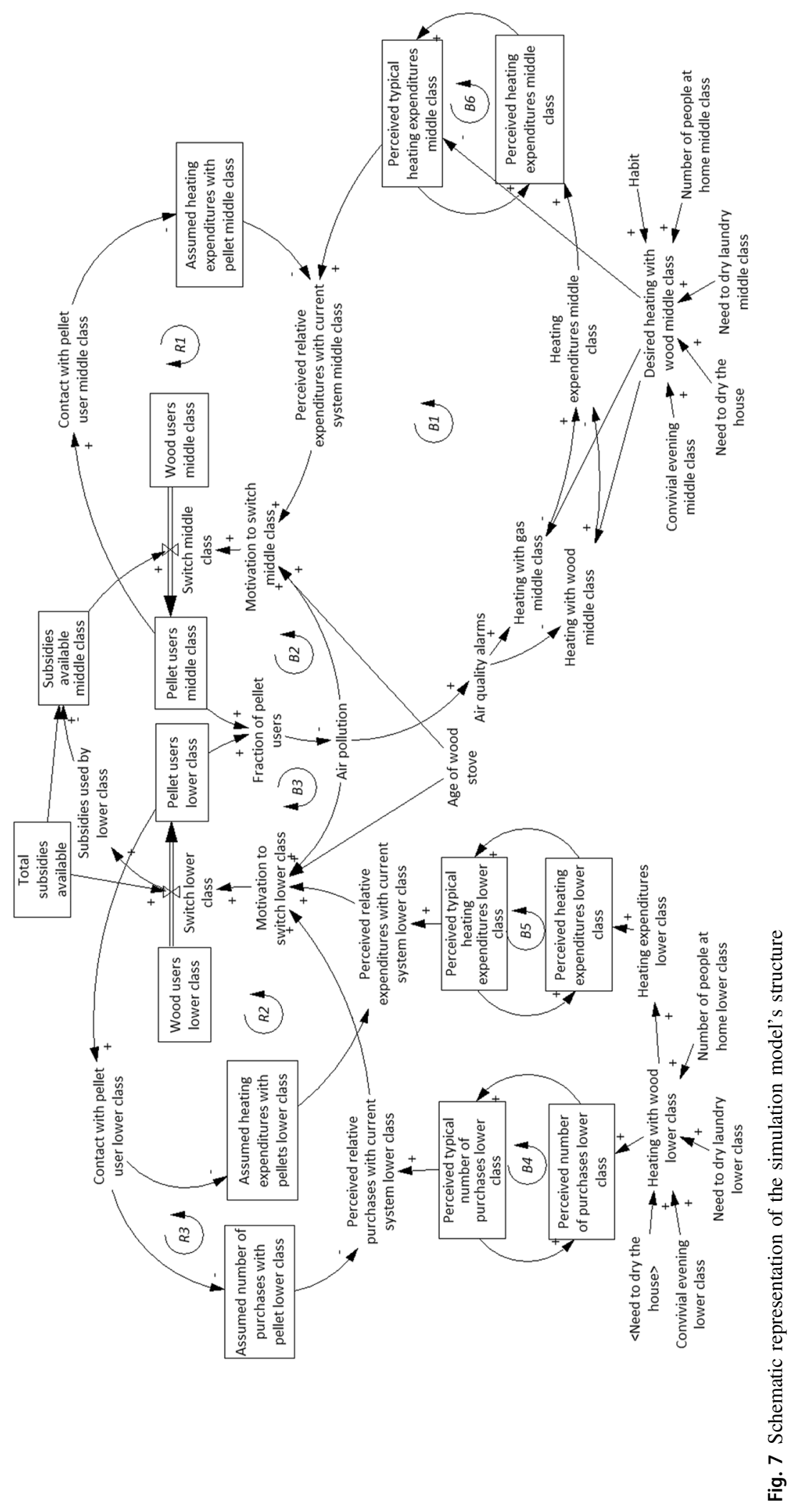


technologies. The results also showed that households usually only interact with people from their own social class. The upper part of Fig. 7 illustrates the word-to-mouth effect, and air pollution is illustrated at the center of the figure.

In the following, the model hypotheses are explained in more detail. Both for a middle- and a low-income household, their respective heating devices are modeled, as well as the aspects that they consider when taking the decision on how to heat on a given day, and on whether they should switch to a different heating technology.

The case of a middle-income household The typical middle-income household has two heating systems at its disposal: a wood and a gas stove. As indicated in the bottom left of Fig. 7, every day, the household chooses which stove to use based on a series of considerations. Namely, if only very few people are in the house, the household chooses to use the smaller gas stove, since not so much heat is needed. When there is a lot of humidity in the house, the household prefers to use the wood stove, since it supposedly better dries the house. When the household has laundry to dry, it also prefers to use the wood stove. Moreover, to ensure that the house is comfortably warm and that tea water is always available, the household also prefers to use the wood stove when there are guests. And since households originally only had a wood stove, in case of doubt, they will choose the wood stove over the gas stove. Lastly, when there is an airquality alarm, the household has to use the gas stove, no matter its original preference for that day.

Aside from the daily decision of whether to use the gas or the wood stove, the household is also considering switching to a pellet stove. The household's motivation to do so depends, as indicated in the center of Fig. 7, on its degree of suffering from air pollution, and on the relative running costs of the pellet stove compared to the household's current heating expenditures. The loop B2 illustrates how when air quality improves as more people switch to pellets, the household's motivation to switch to a pellet stove decreases. And the loop B1 illustrates how the household's current expenditures and consequently its motivation to switch decrease as more people switch to pellets and airquality alarms decrease, enabling the household to use wood more often in its current heating regime. Furthermore, many households are under the impression that the same amount of pellets and wood is required for heating. This belief is, however, biochemically inaccurate, since, if used in an adequate stove, the pellet is much more efficiently combustible than wood (c.f. Universidad de Concepción 2014). This means that they overestimate their expected running costs with a pellet stove, which means that their expected relative running costs with a pellet stove are higher compared to their current ones. Households update their belief based on conversations with pellet users, as is sketched in the top left of Fig. 7 in the loop R1. This phenomenon is reinforced by the fact that households estimate their current heating expenditures based on a hypothetical situation in which they can always use the wood stove when they want to. As air-quality alarms impede them from actually doing so and force them to use their more expensive gas stove, they slowly update their estimates, as shows the loop B6. Furthermore, in its decision of whether or not to switch to a pellet stove, the household also considers the age of its wood stove. Lastly, the household is only willing to switch to a pellet stove if it can access financial assistance to purchase it.

The case of a low-income household The typical lowincome household has a wood stove made out of scrap material. In the case of the low-income household, the daily choice to make is whether to heat at all, since for them, even trash wood is a significant expenditure. They decide based on considerations such as the following: if there are only very few people in the house, the household does not heat. However, when there is a lot of humidity in the house, the household prefers to heat in order to dry the house. Moreover, when there is laundry to dry, the household decides to heat, as well as when they are planning to have a convivial evening with some guests.

Besides the daily decision of whether or not to heat, the household also considers switching to a pellet stove. The household's motivation to accept the governmental subsidy on a pellet stove depends on its degree of suffering from air pollution, the relative running costs of the alternative heating system, and the age of the household's wood stove. Since unlike the typical middle-income household, a typical low-income household does not have a car, it also takes into consideration the number of times per month that it has to purchase combustible-wood or pellets-since this is a complicated task to be accomplished with public transportation. Lastly, just like the typical middle-income household, the typical low-income household is only willing to get a pellet stove if financial assistance for its purchase is provided.

\section{The results from the scenario analysis}

Two scenario sets were developed to analyze how in the decision of whether or not to purchase a cleaner heating technology-a pellet stove-a household's different decision-making priorities and rationales, in interaction with the different air pollution management options, create decision-making dilemmas resulting in environmentally problematic outcomes. The scenarios account for the key areas of uncertainty identified in the conceptual and formal model testing phase. 
Scenarios looking at different policy options This set includes two scenarios. The baseline scenario analyses the responsiveness of households to the government program to achieve a switch to pellet stoves in isolation from other policies. The insulation scenario analyses the responsiveness of households to the government program to achieve a switch to pellet stoves in combination with the government program to subsidize the insulation of houses.

\section{Baseline scenario}

Initially, the typical middle-income household underestimates its heating expenditures, since due the frequent air-quality alarms, it often has to use gas, which is more expensive than wood. As the air-quality alarms keep being frequent over the years, the household adjusts its estimation of its heating expenditures, until it realizes that its current expenditures exceed what it assumes that it would be spending with a pellet stove, as is shown in Fig. 8. Since the household is suffering from air pollution, this is the argument that makes it wanting to switch to a pellet stove, as is shown in Fig. 9, despite the fact that its wood stove is still perfectly functional.

As more and more middle-income households use pellets and relate their experiences with it to the remaining wood users, those realize that they overestimated their likely expenditures with the pellet, as can also be seen in Fig. 8, which motivates even more of them to switch. As Fig. 9 shows, by the end of the third year of the subsidy program, all middle-income households would rather switch to a pellet stove, but only those who can get a subsidy actually do so.

Since the typical low-income household only heats with wood, and sometimes not at all, its heating expenditures are consistently below what it assumes it would be spending with the pellet, and thus make it reluctant to even apply for a subsidized pellet stove.

The results of this scenario show how the middle-income households' underestimation of their current heating expenditures leads to an important response lag to the

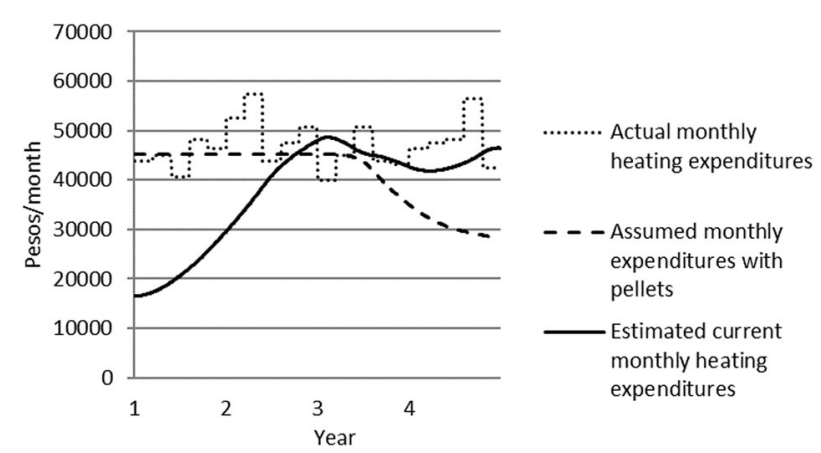

Fig. 8 A middle-income household's perceived and actual heating expenditures subsidy program. Consequently, in the first years of the program, barely any households are motivated to apply, while this demand explodes in the last years of the program. This has to be taken into account in the management of this policy.

\section{Insulation scenario}

In addition to applying for a subsidized pellet stove, households can also apply for subsidies on insulation. All households are keen on obtaining this subsidy and apply for it. Since priority is given to low-income households, middle-income households are only given the subsidy once the demand from low-income households is satisfied. Since the improved insulation reduces the need for heating energy, the households with insulation spend less on heating. These savings have been estimated to be around 20\% (Universidad de Concepción 2014). That a household with insulation spends considerably less on heating means that even for a middle-income household, the pellet no longer seems like a financially attractive option, as can be seen in Fig. 10. Since air pollution also improves slightly as a consequence of the reduced need for heating due to the improved insulation of the houses, resulting in fewer airquality alarms, the middle-income household's motivation to apply for a pellet stove is eroded completely.

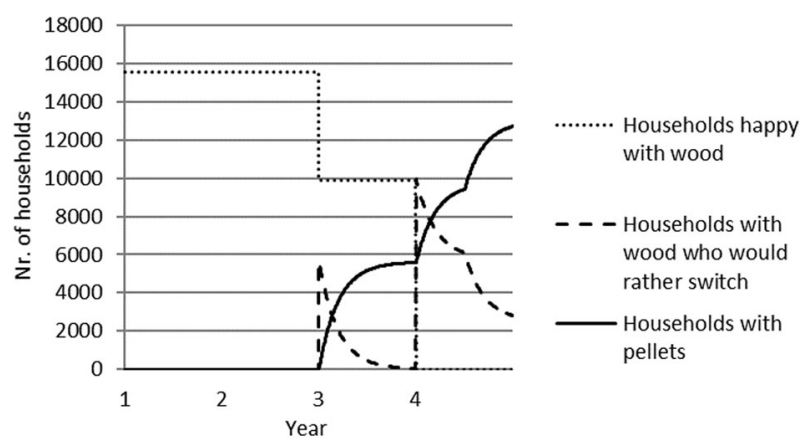

Fig. 9 Heating systems used by middle-income households

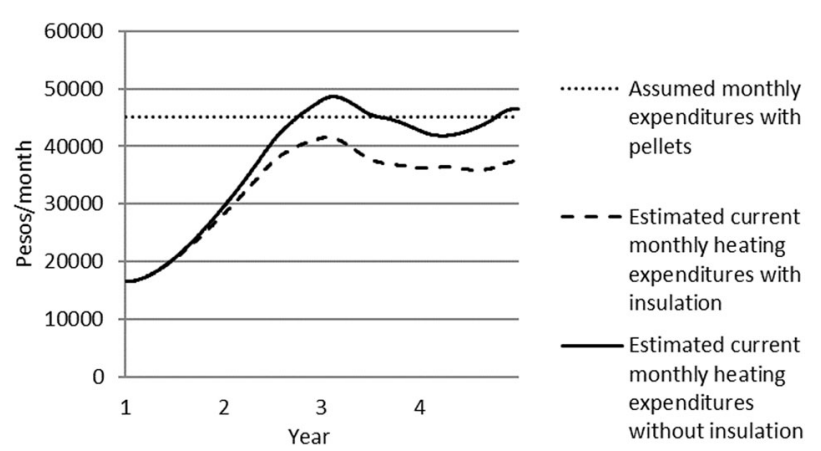

Fig. 10 A middle-income household's perceived expenditures with and without insulation 
The results of this scenario show that there might be crowding-out effects between the insulation program and the program to switch to a pellet stove, which have to be taken into account in the management and implementation of these two policies.

Scenarios addressing the key areas of uncertainty This set also includes two scenarios. Scenario 3, which analyzes the implications of a longer time to adjust the estimated heating expenditures to the lived reality, and scenario 4 , which analyzes the implications of a more substantial improvement of the air-quality due to a switch to pellet stoves.

\section{Adjustment of estimated heating expenditure scenario}

The model has proven to be relatively sensitive to variations of the adjustment time of a household's estimate of its heating expenditures, and, in addition, the follow-up interviews have shown that this parameter might have been underestimated.

If the value of this parameter is increased by $50 \%$, the typical middle-income household only realizes that it could actually save money by switching to a pellet stove by the end of the third year of the program, as is shown in Fig. 11, and the increase in households interested in the subsidy then increases much faster than in the baseline scenario. If the value of this parameter is doubled, virtually no households would have decided to accept the subsidy by the end of the fourth and last year of the program.

Given this uncertainty and its significant implications for the success of the program within its current timeframe, it might have to be considered how households' estimates of their heating expenditures can be corrected with additional policies, which are to be designed for this purpose.

\section{Improvement of air-quality scenario}

As wood stoves are substituted with pellet stoves, airquality improves. The model is based on an estimate regarding the intensity of this effect taken from the report by Universidad de Concepción (2014), but the report admits high uncertainty regarding this estimate. If the effect of a

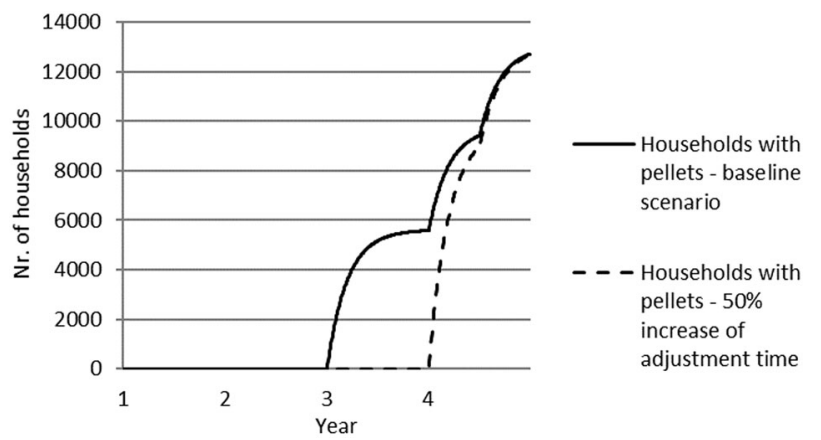

Fig. 11 Pellet stoves used by middle-income households switch to pellet stoves on air pollution is assumed to be more pronounced, the model behavior changes significantly.

As the first wave of households switches to pellets by the end of the second year (c.f. baseline scenario), air-quality improves significantly. This means that there are much less air-quality alarms, due to which the remaining wood users can almost always follow their preference regarding heating either with wood or gas, resulting in lower heating expenditures as compared to the baseline scenario, as is indicated in Fig. 12, so that the pellet no longer is a financially attractive option. Since air pollution also is less of a nuisance, the households are no longer motivated to apply for the subsidy, meaning that a significant number of households remains with wood stoves, as can be seen in Fig. 13.

The results of this scenario show that if the substitution of wood with pellet stoves has a higher than expected impact on air pollution, the desired improvement of the air quality can be achieved without all the households switching. While this looks like a positive outcome-fewer subsidies would be needed to improve the air quality - there is a risk that households might anticipate this outcome and refuse to apply for the subsidy, since being able to use their wood stoves in a context of no air-quality alarms is cheaper than switching to pellet stoves. There is thus a substantial risk of free riding, with households waiting for other households to perform the switch.

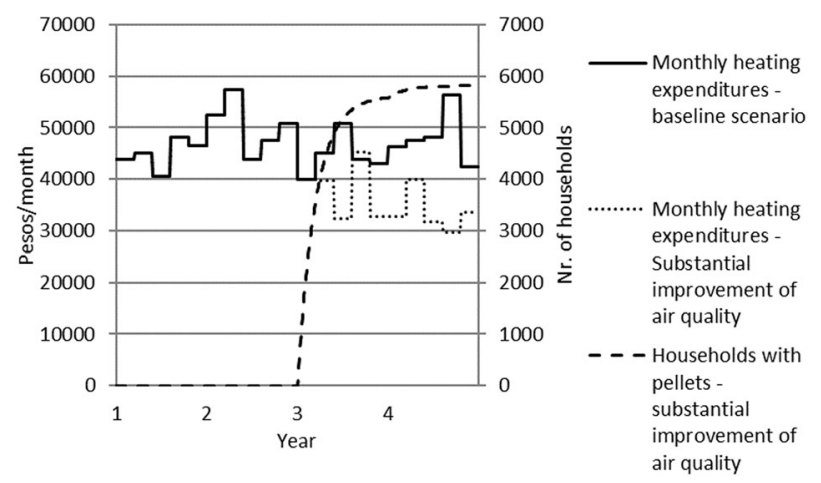

Fig. 12 A middle-income household's monthly heating expenditures

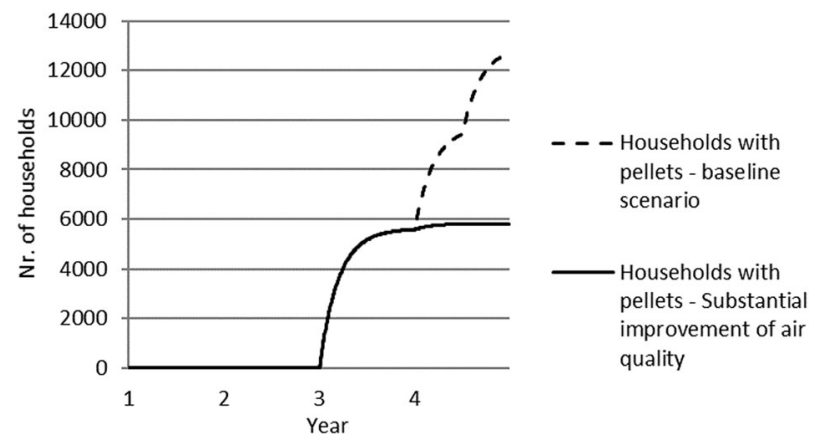

Fig. 13 Middle-income households with pellet stoves 


\section{Discussion}

The insights from the above scenario analyses have shown how the various decision-making rationales that households draw upon when making decisions regarding heating-cost, suffering from air pollution, and the age of their current heating equipment - are affected by the implementation of different policies to overcome the air pollution problem, and how the inter-relatedness of the behavioral rationales underlying the household decisions with the implications of these policies can produce important response lags, or dilemmas that result in crowding-out effects between different policies, or adverse effect such as free riding.

The participatory modeling approach developed for this research project thus allowed not only to identify the key household behavioral rationales, but also how these affect and are affected by different environmental policies, and how the resulting dilemmas impact the effectiveness of these policies regarding the management of the air pollution problem.

The model illustrated how dilemmas can occur either because of tensions between the different rationales that people draw upon when taking decisions regarding heating, or between these rationales and governmental policies to mitigate the air pollution problems. Lastly, it was also illustrated how dilemmas can occur between individual behavioral motivations and aggregated social behavior. The model illustrated how these dilemmas play into aggravating the problem, and therefore allows to anticipate them and adjust the policy interventions in accordance. The model notably highlighted the tension between the wish to keep heating expenditures as low as possible and the desire to breathe clean air, and how different policies played into this. It notably showed that the policy to subsidize insulation-a policy with a significant potential to improve life quality and reduce the need to heat-could lead to perverse effects, where the resulting lower heating expenditures meant that households were not willing to switch to pellet stoves anymore. There is thus also a policy-making dilemma between wanting to improve the quality of the houses, and between reducing air pollution. Our model showed that this dilemma could be overcome by timing the policies differently, meaning by only running the insulation scheme once the pellet stove scheme had been implemented. Our model also highlighted that the tension between these two priorities could result in free riding, thus complicating the implementation of the pellet stove scheme. This phenomenon illustrates a dilemma between the individually preferred strategy - using a wood stove in a context of low air pollution - and the socially preferred strategy, with the majority of households switching to pellet stoves so that air pollution is reduced. This dilemma leads to an environmentally problematic outcome-a lack of households motivated to switch to cleaner technology. In the focus groups, it further emerged that people were well aware of this dilemma, and of the fact that they were the actors of change-yet, their simultaneous desire to keep running costs low paralized them. Our analysis further illustrated that ambiguity in the understanding of the problem context as a driver of environmental problems (c.f. Giordano et al. 2017) also played a role here, in the sense that households associated a different cost function with the use of pellet stoves than policy makers, and that particularly in lowincome households, the solution to solving the problem was not seen as lying in a switch to a different technology, but to a different combustible (dry wood).

Our approach thus proved fruitful to analyze dilemmas that result from the interaction of a household's different decision-making rationales with the decision-making context. Because of having been developed based on a rigorous analysis of the results of focus groups conducted with the population whose behavior the policies aim to change, the model is very adapted to the specific context of the problem. The use of focus groups facilitated the elicitation of the different decision-making rationales that participants mobilized in their decision-making regarding heating, and allowed to shed light on differences between actual and expressed behavior. That people were discussing among equals produced a wealth of arguments that would have been difficult to extract in a more closed format, such as an interview, or one that pushes for more closure, such as group model building. Unlike in a group model-building exercise, where the model is based on a group consensus that corresponds to a new, shared mental model, our approach led to the development of a model that conserved the original individual mental models. Priorization between the many decision-making arguments that emerged during the focus groups was undertaken based on their importance as drivers of the model's dynamics. In this respect, the proposed procedure finds a closer parallel to the knowledge elicitation processes used for abstraction and conceptualization tasks of agent-based models in companion modeling (Becu et al. 2005; Dray et al. 2006; Le Page et al. 2014). However, such procedures are used less often in group model building, with the proposed approach showing a novel way to apply them during a participatory modeling process using System Dynamics. The follow-up interviews with original focus group participants were also important since they contributed to model validation and further ensured that it adequately represents the households' decision-making context, and allowed to elicit parameter values. The combination of the open format of focus groups with the more rigid format of interviews resulted in a rich body of qualitative information on households' decisionmaking processes, as well as in information on specific parameter values and variables. That the focus group script 
took some inspiration from group model building strategies ensured that the resulting information could be broken down into cause and effect variables during the coding process. The rigor of the coding process further ensured traceability and facilitated the management of such a rich body of information. Lastly, working with quantitative models allowed to explore the implications of the different identified dynamics that play into households' decisionmaking processes.

It is, however, to be borne in mind that our approach is most suited for cases where there are only few different mental models present. In our case, the main mental models to consider were the ones of the households, where two actor groups could be distinguished, both, respectively, relatively homogenous: middle-income and low-income households. Our model illustrated in how the decisionmaking rationales of these two differ, and highlighted the interactions between them-in our case, their mutual contribution to the air pollution problem, and the competition for government subsidies for insulation and pellet stoves. Lastly, the mental model of the policy makers was included through their actual policies. If there are more conflicting mental models present in a given case, our approach would still be applicable, but the resulting model would become more complex, since all the different decision-making rationales and their respective interactions would have to be modeled explicitly. In such a case, the question however also needs to be asked whether it would be realistic to design a policy that could take into account all the dilemmas that result from the interaction of such conflicting mental models. It might indeed be more promising in such a case to work with an approach that explicitly fosters convergence of conflicting mental models, such as group model building or a collaborative knowledge production process (c.f. Giordano et al. 2017). Nonetheless, the advantage of our approach is that it allows to identify these potential dilemmas ex ante, and thus to facilitate the decision of whether a co-creative policy design process is required, or whether a policy that takes into account the identified tensions and dilemmas can be designed by the designated decision-maker. In cases of potentially high complexity, it could therefore be promising to combine the approach proposed in this paper with approaches that foster consensus and the co-production of knowledge in a second stage.

\section{Conclusions}

For this study, a novel approach that integrates focus groups with quantitative system dynamics modeling was developed, with the aim to analyze how the inter-relatedness of households' decision-making rationales with their decision- making context is affected by and affects the implementation of environmental policies.

The methodology proved effective to get a better grasp of the diverse motivations and constraints that shape households' decision-making domain, and how these interrelate with environmental policies. The approach combines several of the advantages of the different methods that it draws upon, and consequently overcomes some of the issues that are frequently encountered when studying environmental problems that result from the dilemmas inherent to complex decision-making contexts. By eliciting people's decisionmaking rationales and explicitly modeling them, the approach results in a model that makes realistic assumptions about people's decision-making processes. The use of System Dynamics modeling emphasizes the dynamic implications of the inter-relatedness of the tensions that a person faces in her decision-making context. Such insights can be used ex ante to design environmental policies, which explicitly take into account the decision-making rationales of people, and allow to anticipate and mitigate potential unintended negative consequences of the policy. The use of focus groups allowed to identify potential discrepancies between how people express to act and how they really act, and to elicit behaviors or beliefs that people were not proud of. The integration of group model building scripts into the focus group script facilitated the use of the resulting data for the development of a simulation model. The rigorous coding of the qualitative information based on the principles of grounded theory ensured the closeness of the model to the households' perception of the problem domain, as well as traceability and transparency of the process, and helped to avoid losing the richness of the original data in the modeling process. The use of a coding strategy aimed at the development of a simulation model also helped to avoid getting lost in the richness of people's narratives. Lastly, the use of group interviews at the validation stage overcame the challenge of quantifying largely qualitative variables and parameters.

Our approach, if standing alone, is best suited for a problem context with a relatively small amount of different mental models. If there are many diverging viewpoints, the resulting models risk getting very complex. In such cases, it might be beneficial to combine the approach proposed here with other methods (e.g., companion modeling, knowledge co-production, or group model building) or add a second stage in which the collected information is used as the starting point to a participatory exercise with the aim of aligning the different mental models and representations of the problem context. In such an exercise, the System Dynamics model could on the one hand be used as a learning tool to foster individuals' understanding of the implications of their decisions, and on the other hand as a boundary object to foster a dialog between stakeholders and 
policy makers, in order to improve their understanding of their mutual position in the system and the roots of each other's behavior. In future research, it could therefore be interesting to explore this possibility of coupling our approach with one that fosters consensus.

Acknowledgements The authors acknowledge the Corporación de Desarrollo of the city of Talca and Prof. Martin Schaffernicht from the Universidad de Talca for their help in initiating and setting up the case study, as well as the collaboration of the local participants. The authors also acknowledge the New University of Lisbon, Portugal, the University of Bergen, Norway, the University of Palermo, Italy, and the Radboud University, The Netherlands, for capacitating the undertaking of this research within the European Master Programme in System Dynamics (EMSD). The first author was supported by the EACEA (Education, Audiovisual and Culture Executive Agency of the European Commission) during the EMSD programme. CENSE is supported by the Portuguese Foundation for Science and Technology through the strategic project UID/AMB/04085/2013.

\section{Compliance with Ethical Standards}

Conflict of Interest The authors declare that they have no conflict of interest.

\section{References}

Ajzen I (1991) The theory of planned behaviour. Organ Behav Hum Dec 50:179-211

Andersen DF, Richardson G (1997) Scripts for group model building. Syst Dynam Rev 13:107-129

Andersen DL, Luna-Reyes LF, Diker VG, Black L, Rich E, Andersen DF (2012) The disconfirmatory interview as a strategy for the assessment of system dynamics models. Syst Dynam Rev 28 (3):255-275

Armah FA, Yawson DO, Pappoe ANM (2010) A system dynamics approach to explore traffic congestion and air pollution link in the city of Accra, Ghana. Sustainability 2:252-265

Barlas Y (1996) Formal aspects of model validity and validation in system dynamics. Syst Dynam Rev 12(3):183-210

Becu N, Barreteau O, Perez P, Saising J, Sungted S (2005) A methodology for identifying and formalizing farmers representation of watershed management : a case study from northern Thailand. In: Bousquet F, Trébuil G, Hardy B (eds) Companion modeling and multi-agent systems for integrated natural resource management in Asia. CIRAD, IRRI, Metro Manila, pp 41-62

Bousquet F, Barreteau O, Le Page C, Mullon C, Weber J (1999) An environmental modelling approach. The use of multi-agents simulations. In: Blasco F, Weill A (eds) Advances in environmental and ecological modelling. Elsevier, Paris, pp 113-122

Cárdenas JC, Stranlund C, Willis C (2000) Local environmental control and institutional crowding-out. World Dev 28 (10):1719-1733

Carmona G, Varela-Ortega C, Bromley J (2013) Participatory modelling to support decision making in water management under uncertainty: Two comparative case studies in the Guadiana river basin, Spain. J Environ Manag 128:400-412

Charmaz K (2006) Constructing grounded theory: a practical guide through qualitative analysis. Sage Publications, London

Chávez C, Gómez W, Briceño S (2009) Costo-efectividad de instrumentos económicos para el control de la contaminación. El caso del uso de leña. Cuad De Econ 46:197-224. Noviembre
Chávez CA, Stranlund JK, Gómez W (2011) Controlling urban air pollution caused by households: uncertainty, prices, and income. J Environ Manag 92:2746-2753

Chen MC, Ho TP, Jan CG (2006) A system dynamics model of sustainable urban development: assessing air purification policies at Taipei City. Asian Pac Plan Rev 4(1):29-52

Chen H, Chang YC, Chen KC (2014) Integrated wetland management: an analysis with group model building based on system dynamics model. J Environ Manag 146:309-319

Costanza R, Ruth M (1998) Using Dynamic Modeling to Scope Environmental Problems and Build Consensus Environmental Management 22:183. https://doi.org/10.1007/s002679900095

Coyle G (2000) Qualitative and quantitative modelling in system dynamics: some research questions. Syst Dyn Rev 18: 225-244

Crance C, Draper D (1996) Socially cooperative choices: an approach to achieving resource sustainability in the coastal zone. Environ Manag 20(2):175-184

Dray A, Perez P, Jones N, Le Page C, d'Aquino P, White I, Auatabu T (2006) The AtollGame experience: from knowledge engineering to a computer-assisted role-playing game. J Artif Soc Soc Simul 9 (1):1-6. http://jasss.soc.surrey.ac.uk/9/1/6.html

Dupont H, Gourmelon F, Rouan M, Le Viol I, Kerbiriou C (2016) The contribution of agent-based simulations to conservation management on a Natura 2000 site. J Environ Manag 168: $27-35$

Elsawah S, Guillaume JHA, Filatova T, Rook J, Jakeman AJ (2015) A methodology for eliciting, representing, and analysing stakeholder knowledge for decision making on complex socioecological systems: from cognitive maps to agent-based models. J Environ Manag 151:500-516

Farnsworth J, Boon B (2010) Analysing group dynamics within the focus group. Qual Res 10(5):605-624

Forrester JW (1992) Policies, decisions and information sources for modelling. Eur J Oper Res 59:42-63

Giordano R, Brugnach M, Plucchinotta I (2017) Ambiguity in problem-framing as a barrier to collective actions: Some hints from groundwater protection policy in the Apulia region. Group Decis Negot 26(5):911-932

Gómez W, Yep S, Chávez C (2013) Subsidios a hogares para inducir adopción de tecnologías de combustión de leña más eficiente y menos contaminantes: Simulación para el caso de Temuco y Padre Las Casas. Estud De Econ 440(1):21-52

Jones NA, Perez P, Measham TG, Kelly GJ, d'Aquino P, Daniell KA, Dray A, Ferrand N (2009) Evaluating participatory modeling: Developing a framework for cross-case analysis. Environ Manag 44:1180-1195

Kelly (Letcher) R, Jakeman A, Barreteau O, Borsuk M, ElSawah S, Hamilton S, Henriksen HJ, Kuikka S, Maier H, Rizzoli A, van Delden H, Voinov A (2013) Selecting among five common modelling approaches for integrated environmental assessment and management. Environ Model Softw 47:159-181

Kim H, Anderson DF (2012) Building confidence in causal maps generated from purposive text data: mapping transcripts of the Federal Reserve. Syst Dynam Rev 28:311-328

Kind L (2004) Notas para o trabalho com a técnica de grupos focais. Psicol em Rev 10(15):124-136

Kitzinger J (1994) The methodology of focus groups: the importance of interaction between research participants. Sociol Health Ill 16 (1):103-121

Kollmuss A, Agyeman J (2002) Mind the gap: why do people act environmentally and what are the barriers to pro-environmental behaviour? Environ Educ Res 8(3):239-260

Lavallee A, Hower T, Hovmand P (2010) Scriptapedia/Debriefing. https://en.wikibooks.org/wiki/Scriptapedia 
Leal Neto A, de C, Legey LFL, González-Araya MC, Jablonski S (2006) A system dynamics model for the environmental management of the Sepetiba Bay watershed, Brazil. Environ Manag 38:879-888

Lemons J (1989) The need to integrate values into environmental curricula. Environ Manag 13(2):133-147

Le Page C, Abrami G, Barreteau O, Becu N, Bommel P, Botta A, Dray A, Monteil C, Souchère V (2014) Models for sharing representations. In: Etienne M (ed) Companion modelling. Springer, Versailles, pp 69-101

Luna-Reyes LF, Andersen D (2003) Collecting and analysing qualitative data for system dynamics: methods and models. Syst Dyn Rev 19:271-296

Martínez-Alier J, Muradian R (2015) Handbook of ecological economics. Edward Elgar Publishing, Cheltenham

Max-Neef M (1991) Human scale development: conception, application and further reflections. The Apex Press, New York

Meadows DH (1976) The unavoidable a priori. Proceedings of the 1976 International Conference of the System Dynamics Society, Geilo,161-240

Ministerio del Medio Ambiente (2014) Planes de descontaminación atmosférica: Estrategia 2014-2018. Gobierno de Chile, Santiago

Ministerio del Medio Ambiente (2015) Plan de descontaminación atmosférica para las comunas de Talca y Maule. Gobierno de Chile, Santiago

Mostashari A, Sussman J (2005) Stakeholder-assisted modelling and policy design process for environmental decision-making. J Environ Assess Policy Manag 7(3):355-386

Paavola J, Adger WN (2005) Institutional ecological economics. Ecol Econ 53:353-368

Popa F (2015) Motivations to contribute to public goods: beyond rational choice economics. Environ Policy Gov 25:230-242

Reed MS, Graves A, Dandy N, Posthumus H, Hubacek K, Morris J, Prell C, Quinn CH, Stringer LC (2009) Who's in and why? A typology of stakeholder analysis methods for natural resource management. J Environ Manag 90:1933-1949

Renn O, Schweizer PJ (2009) Inclusive risk governance: concepts and application to environmental policy-making. Environ Policy Gov 19:174-185

Ringrose S, Chanda R, Nkambwe M, Sefe F (1996) Environmental change in the Mid-Boteti area of north-central Botswana: biophysical processes and human perceptions. Environ Manag 20 (3):397-410

Romm NRA (2015) Conducting focus groups in terms of an appreciation of indigenous ways of knowing: some examples from South Africa. Forum Qualitative Sozialforschung 16(1):Article No. 2

Rouwette EAJ, Vennix JAM, Van Mullekom T (2002) Group model building effectiveness. A review of assessment studies. Syst Dynam Rev 18:5-45
Sanhueza L, Mardones C, Jiménez J (2015) Efectos de la incorporación de fuentes residenciales en mecanismos de compensación de emisiones industriales de PM10. Rev Int Contam Ambient 31 (3):279-291

Santos R, Antunes P, Baptista G, Mateus P, Madruga L (2006) Stakeholder participation in the design of environmental policy mixes. Ecol Econ 60:100-110

Shahgholian K, Hajihosseini H (2009) A dynamic model of air pollution, health, and population growth using system dynamics: A study on Tehran-Iran (with computer simulation by the software Vensim). Int J Environ 3(11):372-379

Shortle JS, Horan RD (2001) The economics of nonpoint pollution control. J Econ Surv 15(3):255-289

Stave KA (2010) Participatory system dynamics modelling for sustainable environmental management: observations from four cases. Sustainability 2:2762-2784

Sterman JD (2000) Business dynamics - Systems thinking and modelling for a complex world. Irwin McGraw-Hill, Boston

Stern PC, Fineberg HV (1996) Understanding risk: Informing decisions in a democratic society. National Academy Press, Washington, DC

Stringer LC, Fleskens L, Reed MS, de Vente J, Zengin M (2014) Participatory evaluation of monitoring and modeling of sustainable land management technologies in areas prone to land degradation. Environ Manag 54:1022-1042

Universidad de Concepción (2014) Diagnóstico de la calidad del aire y medidas de descontaminación en Talca y Maule - 2012-6147977-LP12 - Informe Final. Universidad de Concepción, Concepción

Vennix JAM (1990) Mental models and computer models: design and evaluation of a computer-based learning environment. Dissertation, Radboud University of Nijmegen

Vennix JAM (1996) Facilitating team learning using system dynamics. Wiley, Chichester

Vidal-Legaz B, Martínez-Fernández J, Sánches Picón A, Pugnaire FI (2013) Trade-offs between maintenance of ecosystem services and socio-economic development in rural mountaineous communities in southern Spain: a dynamic simulation approach. J Environ Manag 131:280-297

Videira N, Antunes P, Santos R, Lobo G (2006) Public and stakeholder participation in European water policy: a critical review of project evaluation processes. Eur Environ 16:19-31

Videira N, Antunes P, Santos R, Lopes R (2010) A participatory modelling approach to support integrated sustainability assessment processes. Syst Res Behav Sci 27:446-460

Voinov A, Bousquet F (2010) Modelling with stakeholders. Environ Model Softw 25:1268-1281. https://doi.org/10.1016/j.envsoft. 2010.03.007Xu

Xu J, Kang J, Shao L, Zhao T (2015) System dynamics modelling of industrial growth and landscape ecology in China. J Environ Manag 161:92-105 